\title{
Moderating Role of Demographic Characteristics in Breast Cancer Awareness and the Behavioural Disposition of Women in Ogun State, Nigeria
}

Tolulope Abiola Allo ${ }^{1^{*}}$, David Imhonopi ${ }^{2}$, Emmanuel O. Amoo ${ }^{3}$, Tunde C. Iruonagbe ${ }^{2}$, Ajibade E. Jegede $^{2}$, Lady A. Ajayi ${ }^{4}$, Faith O. Olanrewaju ${ }^{4}$, Paula M. Ajayi ${ }^{2}$, Adebanke Olawole-Isaac ${ }^{3}$

${ }^{1}$ Department of Sociology, Covenant University, Ota, Nigeria; ${ }^{2}$ Department of Sociology, Covenant University, Ota, Nigeria; ${ }^{3}$ Demography and Social Statistics, Covenant University, Ota, Nigeria; ${ }^{4}$ Department of Political Science and International relations, Covenant University, Ota, Nigeria

Citation: Allo TA, Imhonopi D, Amoo EO, Iruonagbe TC, Jegede AE, Aiayi LA, Olanrewaju FO, Ajayi PM, OlawoleIsaac A. Moderating Role of Demographic Characteristics in Breast Cancer Awareness and the Behavioura Disposition of Women in Ogun State, Nigeria. Ope Access Maced J Med Sci. 2019 Oct 15; 7(19):3281-3286

Keywords: Awareness; Breast cancer; Behavioura disposition; Nigeria; Women

Correspondence: Tolulope Abiola Allo. Department Sociology, Covenant University, Ota, Nigeria. E-mail: tolu.allo@covenantuniversity.edu.ng

Received: 26-May-2019; Revised: 16-Jul-2019; Accepted: 17-Jul-2019; Online first: 25-Aug-2019

Copyright: ๑ 2019 Tolulope Abiola Allo, David Imhonopi, Emmanuel 0 . Jegede, Lady A. Ajayi, Faith O. Olanrewaju, Paula M. Ajayi, Adebanke Olawole-lsaac. This is an open-access article distributed under the terms of the Creative Commons Attribution-NonCommercial 4.0 Internationa

Funding: This research received financial support from he Covenant University Centre for Research Innovation and Discovery (CUCRID), Nigeria

Competing Interests: The authors have declared that no competing interests exis

\section{Abstract}

BACKGROUND: Breast cancer incidence is fast increasing, posing a significant threat to the health of women of all races globally. In Nigeria, breast cancer causes the most cancer-related deaths among women each year as a result of inadequate awareness.

AIM: This study is aimed at examining the moderating role of demographic characteristics in facilitating breas cancer awareness among women, and how it relates to their behavioural disposition to the disease.

METHODS: The study adopted the descriptive (survey) and cross-sectional research designs to elicit information from women of adult age selected across five Local Government Areas in Ogun state. The data, collected through questionnaire were analysed through the use of a variance-based SEM Partial Least Square (PLS).

RESULTS: The result shows that demographic characteristics (age and education) has a significant positive effect and jointly explain $74.9 \%$ of the variance in the breast cancer awareness and behavioural disposition among women in the study area. The findings revealed that a significant number of women with breast cancer had not acquired useful knowledge that could potentially be used to diagnose, prevent, and manage the disease. Unfortunately, the practice of Breast Self-Examination is grossly low among Nigerian women, as a consequence only $20-30 \%$ of the women in study areas, including professionals, are aware of the benefits of BSE and only a smaller percentage practice BSE.

CONCLUSION: There is, therefore, a need to educate women on the benefits of this simple life-saving procedure through the consistent use of media platforms.

\section{Introduction}

Breast cancer is fast becoming a global epidemic, constituting a significant threat to the health of women of all races. Statistics revealed that it accounts for about $23 \%$ of all cancer incidences [7] [22], with Over 1 million breast cancer cases reported each year. It has also been reported that over 411,000 deaths occur annually representing $14 \%$ of female cancer-related deaths worldwide [6].

Going by all of these statistics, it is evident that the prevalence of breast cancer is increasing worldwide, and a steady upsurge in its incidence has been observed in both developed and developing countries [5], [7], [22], [30]. In most developed countries, medical care is personalised with patients being offered scientific and evidence-based treatment. Unfortunately, in developing countries like Nigeria, a significant number of women may not benefit from evidence-based best practice due to the multi-faceted and multi-sectoral problems ravaging the country's health care delivery system. With the current economic downturn, the health care sector is worse off with regard to public healthcare expenditure [4].

There are significant challenges associated with accessing quality and affordable health care in Nigeria. For instance, health care services are largely inaccessible and unaffordable especially for the urban 
poor and women residing in rural areas. The whole gamut of health care delivery system in the country is almost in a state of comatose as a result of inadequate funding, poor maintenance culture and a lack of genuine commitment by the government [2], [25]. Health care in Nigeria is characterised by poor and inadequate basic infrastructure, obsolete and dilapidating medical equipment, poor and inadequate distribution of health workers, poor quality of healthcare services, lack of essential drug supply, and, corruption. [4], [13], [14]. Radiotherapy and chemotherapy treatments for breast cancer in Nigeria are expensive and unaffordable [28], complicated by poor awareness about the disease among women. This may explain why many women are left with the option of alternative and unorthodox treatment, and it may also be one of the reasons for late presentation to hospitals at a more challenging stage with attendant poor prognosis leaving the patient with little or no hope for survival [32], [28].

Most breast cancer patients often present with the advanced stage of the disease with high-grade infection load on the breast and metastasis [10], [33], [20]. Available treatment facilities are few and unevenly distributed, with the presence of old and broken radiotherapy machines and equipment [28], [9]. Accessibility and cost are major limiting factors why many African women cannot access simple lifesaving treatments [26].

Extant literature has identified a direct link between breast cancer awareness and behavioural disposition. For instance, studies by Justo, Wilking, Jönsson, Luciani and Cazap (2013), and that of Ganiyu and Ganiyu (2012) have shown that the most pressing element influencing the relationship between knowledge creation and performance could be as a result of socio-demographic factors which may include gender, age, education, locality and a number of other factors. However, the relationship between and among these variables have not been fully explored and established. This study, therefore, shall attempt to focus on the moderating role of some identified demographic variables in the facilitation of breast cancer awareness, and the behavioural disposition of women to the disease in Ogun state.

\section{Problem Statement}

While most women are aware of breast cancer, many lack adequate knowledge about the steps to take to detect the disease in its early stage [3]. In the late 80 s and early 90 s, studies on the level of knowledge and awareness of breast cancer revealed that women generally are oblivious of the disease, especially its risk factors and treatment options. Recent studies, however, have shown an increase in the knowledge level of breast cancer, especially among women in more developed societies. But the same cannot be said of women in developing countries, especially those in the Sub- saharan region of Africa where awareness is still relatively low with limited access to timely and accurate information

In Nigeria, breast cancer has been reported to have accounted for about $56.6 \%$ of all cancer diagnosis [35], with about $70 \%$ of Nigerian women presenting late with the advanced stage of the disease. In low-and-middle-income countries like Nigeria, one of the identifiable causes for late presentation is ignorance, because "women are still afraid to know of their diagnosis", coupled with poor health education [23]. According to Jedy-Agba et al., 2017 ", the stage at diagnosis is a reflection of the degree of awareness of the disease in the population". $A$ recent projection perceives global cancer burden doubling between this current time and the year 2030 with the majority of this burden falling on low income and lower-middle-income countries (LMCs) because of limited resources to deal with the disease and partly because of low levels of awareness [15].

\section{Literature Review}

In the past, there was a great deal of shame surrounding breast cancer. This was because it affects what was considered a "private part" of a woman's body which is so closely tied to her sexuality, maternity and feminine identity. Women were ashamed to disclose their diagnosis publicly and may even outrightly refuse to be examined or diagnosed at all [6]. In the present time, women are gradually becoming more open to the discussion of breast cancer and are relatively aware of the disease. Breast awareness among women is central to the correct and accurate recognition of breast cancer symptoms which is believed will help in expediting action for treatment, thereby increasing the hope of survival [19].

Death rates from breast cancer have reduced significantly in the United States largely because of better screening and early detection, increased awareness and improvement of treatment options [7]. This has translated to an increment in the rate of survivors, given that well over 3.3 million breast cancer survivors are alive in the US today [6]. The situation is, however, unfortunately, different in Nigeria, where women still have limited knowledge about the disease and eventually die as a result of ignorance.

Many women, especially women in rural areas in Nigeria, think breast cancer was a mere infection that could be easily cured with drugs [36]. This revelation is an indicator of the fact that breast cancer knowledge level, especially among rural women, is still very questionable. Women living in rural areas constitute an underserved population and are characteristically riddled with a lot of health challenges. Reports from past studies have shown that health and media facilities are limited in most 
rural communities in Nigeria, making rural women less likely to have adequate health information [38]. This situation may impede their access to adequate information on breast cancer and put them at risk of the disease.

It was reported in one study that, only $1.9 \%$ of rural women acknowledged a painless lump as an early warning sign of breast cancer [37]. It was also revealed in a recent study that, $80.4 \%$ of 316 women respondents claimed to have ever heard of breast cancer while only a few displayed a good knowledge of its causes (12.6\%) and symptoms (13\%) [21]. Knowledge and awareness of breast cancer were, however, appreciable among women living in urban centres. A sample of the opinion of women about their knowledge of breast cancer symptoms, risk factors, prevention methods and treatment options showed that urban women (55.61\%) were more knowledgeable than rural women (47.81\%) [38]. Knowledge is indeed central to the curtailment of breast cancer as knowledge empowers and liberates from ignorance. For women to present early to the hospital, they need to be breast aware, and they must be able to recognise the symptoms of breast cancer [18], [34], and for this to happen they need to be equipped with accurate and timely information. The right information about breast cancer will enable women to detect their symptoms early and seek medical attention on time.

Lack of early detection has been documented in the literature as the bane of most breast cancer deaths [11], especially in the sub-Saharan region of Africa. This, in turn, has been blamed on poor awareness. As noted by Badar et al., (2007), knowledge about breast cancer is a fundamental element necessary for its early detection, prevention and treatment. According to Omaka-Amari, Ilo, Nwimo, Onwunaka and Umoke (2015), knowledge was conceived as the possession of an accurate understanding of breast cancer, its symptoms, risk factors, prevention and treatment options. To them, adequate knowledge will equip women with the ability to observe and correctly identify symptoms of breast cancer promptly before it begins to metastasize. It will also empower women to seek medical assistance promptly [8]. Knowledge of breast cancer risk factors will also help in its prevention by the adoption of appropriate measures and lifestyles.

Before a country like Nigeria can begin to experience an appreciable rise in the rate of breast cancer survival, women must possess the basic knowledge about breast cancer prevention. This involves the adoption of three screening approaches as suggested by Modeste, Caleb-Drayton and Montgomery (1999). These approaches are Breast Self-Examination (BSE), Clinical Breast Examination (CBE) and Mammography. BSE is a monthly procedure usually recommended for women starting from age 20. CBE is to be observed by women between the ages of 20-39 years every 3 years. It is however expected that women who are 40 years and above should have it done every year [11]. Mammography is a procedure recommended for women who are above 40 years and is usually advised to be done every one or two years.

The knowledge of different options available in the treatment of breast cancer is also central to the curtailment of the disease. Essentially, women should be equipped with accurate information about these treatment options to be able to make informed decisions about their well-being. The four basic treatment options for breast cancer are surgery, chemotherapy, radiation and hormone therapy [1]. The knowledge about available breast cancer treatment centres is another key factor that can further reduce breast cancer fatalities in Nigeria [38]. When women are equipped adequately with these information, they will be better informed about their options which will, in turn, influence their healthseeking behaviour

\section{Methodology}

The study adopted the descriptive (survey) and cross-sectional research designs. The descriptive (survey) method was adopted for this study because of its high propensity for representativeness and its ability for wider coverage of respondents. Quantitative data were thus elicited from women in their reproductive years and post-menopausal women aged $15-69$ years.

The area under investigation with regards to this study is Ogun State. It is located in the Southwestern region in the Federal Republic of Nigeria. Ogun state is one of the 36 states in the country with a total land area of $16,980.55$ sq. km [29]. It consists of 3 senatorial districts, 9 federal constituencies, 27 State constituencies and 20 Local Government Areas [31]. The population of interest with regard to this study are women selected across the 20 LGAs of Ogun State. Although previous studies have reported that breast cancer peaks between age 45 and 55 years [12], [41], this study covered women between age $15-69$ years because findings from the literature suggest that these age groups are the most vulnerable to breast cancer and vulnerability increases with age.

The multi-stage sampling technique was adopted in the selection of respondents for this study. The sample population was drawn from over 880,970 regular households distributed unevenly across the 20 LGAs in Ogun State [29]. The first stage of the sampling process involved the stratification of the 20 LGAs according to their population size. The second stage involved a random selection of 5 out of the 12 densely populated LGAs. The lottery method was used in making this selection. The 5 selected LGAs are Ado-Odo Ota; Abeokuta South; Sagamu; Obafemi Owode and ljebu Ode. The third stage involved the 
selection of one ward from each of the selected LGAs using the lottery method. Out of the ward selected from each of the LGAs, streets were selected using the purposive sampling method, while, the systematic sampling method was adopted in the selection of residential houses in selected streets. One household was selected in every 5th house to ensure everyone was given an equal non-zero chance of being selected. The final stage of the sampling process involved the selection of respondents in selected households. All women aged 15-69 years were given equal chances of being selected in every household sampled. A sample size of 280 female respondents was randomly selected from the total population of 901 , comprising $31 \%$ of the total population. The questionnaire titled "Awareness and Behavioural Disposition to Breast Cancer among Women" (ABCWQ) was used for data collection.

The questionnaire was administered to all females that fall between the ages of 15-69 years, and the completed questionnaire was collected on the spot. The services of field assistants were sought in this regard, and they have been duly trained appropriately before the commencement of the data collection. To ensure data quality, the collected questionnaire was checked and edited for coherence and consistency before sending them for analysis.

\section{Ethical Consideration}

Approval was sought from the Ethical Committee of the University of the researchers, and verbal informed consent of participants was duly obtained. Participants were debriefed about the aim and objectives of the study before the data collection process commenced. Participants were also assured of privacy, anonymity and confidentiality of the information supplied.

\section{Reliability and Validity of Research Instrument}

The research instrument was presented to management experts in the field for validity check while the test and re-test method was used to establish construct reliability [16] and validity as presented in Table 1.

Table 1: Construct Reliability and Validity

\begin{tabular}{|c|c|c|c|c|}
\hline & $\begin{array}{l}\text { Cronbach_ } \\
\text { Alpha }\end{array}$ & rho_A & $\begin{array}{l}\text { Composite } \\
\text { Reliability }\end{array}$ & $\begin{array}{l}\text { Average Variance } \\
\text { Reliability }\end{array}$ \\
\hline Threshold & $>0.7$ & $>0.7$ & $>0.7$ & $>0.5$ \\
\hline $\begin{array}{l}\text { Awareness level of } \\
\text { Breast Cancer }\end{array}$ & 0.962 & 0.970 & 0.982 & 0.971 \\
\hline $\begin{array}{l}\text { Behavioural } \\
\text { Disposition }\end{array}$ & 0.851 & 0.888 & 0.942 & 0.893 \\
\hline $\begin{array}{l}\text { Demographic } \\
\text { characteristics }\end{array}$ & 0.711 & 0.728 & 0.741 & 0.597 \\
\hline $\begin{array}{l}\text { Through breast self- } \\
\text { examination }\end{array}$ & 0.744 & 0.801 & 0.954 & 0.941 \\
\hline $\begin{array}{l}\text { Through health } \\
\text { service provider }\end{array}$ & 0.759 & 0.765 & 0.849 & 0.760 \\
\hline Through media & 0.799 & 0.805 & 0.961 & 0.878 \\
\hline Through Relatives & 0.715 & 0.722 & 0.770 & 0.629 \\
\hline
\end{tabular}

Five research questions and hypotheses were tested using inferential statistics such as measurement and structural models. The analyses were done through the use of a variance-based SEM Partial Least Square (PLS) as suggested by Fornell and Larcker (1981).

\section{Results}

The PLS-SEM path model was adopted to establish the awareness level of breast cancer (through breast self-examination $(\mathrm{H} 1)$, the health service provider ( $\mathrm{H} 2)$, Media $(\mathrm{H} 3)$ and Relatives $(\mathrm{H} 4)$, and the impact on the behavioural disposition of women. The moderating role of demographic characteristics (H5) was also assessed to explain the relationship between the variables as presented in Figure 1.

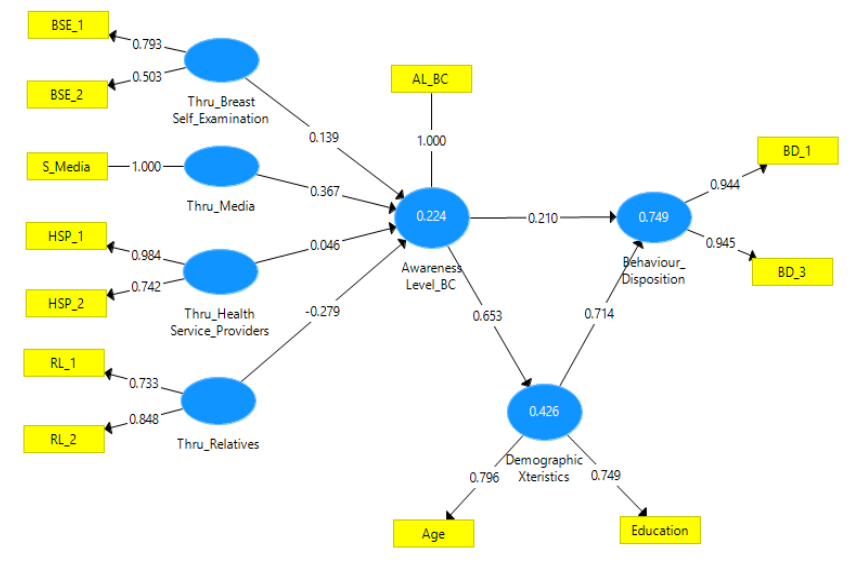

Figure 1: PLS-SEM Path Co-efficient Model

Figure 1 showed the moderating role of demographic characteristics (age and education) on the relationship between the awareness level of breast cancer and behavioural disposition of women using variance-based structural model. Based on the statistical result, it was found that there was a significant direct relationship between the awareness level of breast cancer and behavioural disposition among women, though the correlation coefficient $(0.210)$ is weak. All the findings except "through relatives" were held significant at the 0.05 probability level. Findings also revealed that only $20-30 \%$ of the women in study areas, including professionals, know of the benefits of Breast Self-Examination (BSE) and only a smaller percentage practice it.

Essentially, demographic characteristics (age and education) had a very strong significant and positive effect on the awareness level of breast cancer among the women in the study area. In the same vein, demographic characteristics (age and education) had a stronger significant relationship in moderating the 
awareness level of breast cancer and behavioural disposition to the disease among the women. Importantly, the total variance explained by the model as a whole was $74.9 \%$. This also implies that the tested measures of demographic characteristics (age and education) jointly explain $74.9 \%$ of the variance in the level of awareness on breast cancer and behavioural disposition among the women in the study area.

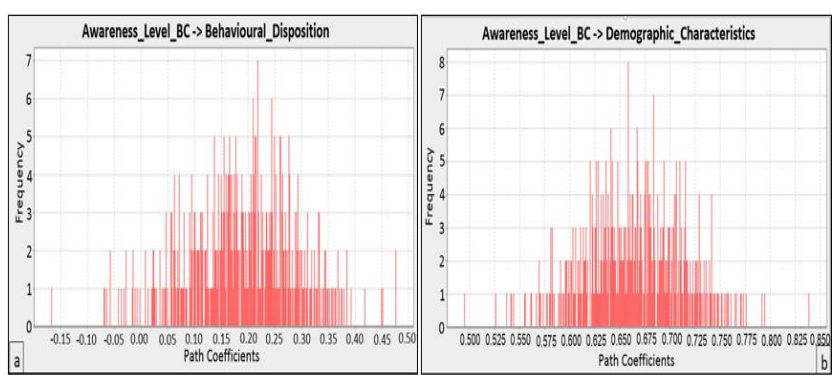

Figure 2: A) Path Coefficients Histogram for Awareness Level of Breast Cancer and Behavioural Disposition among Women; B) Path Coefficients Histogram for Awareness Level of Breast Cancer among Women and Demographic Characteristics

Under each null hypothesis, bootstrapping resampling, which indicates the statistical power of the proposed tests and their sensitivity concerning the size of the co-efficient has been performed to obtain the bootstrap approximation using the histogram path co-efficient. Hence, the histograms of the bootstrap approximations of the GoF distributions under the null hypotheses for Test 1 , Test 2 , Test 3 , Test 4 and Test 5 were presented in the Figures 2 and 3.

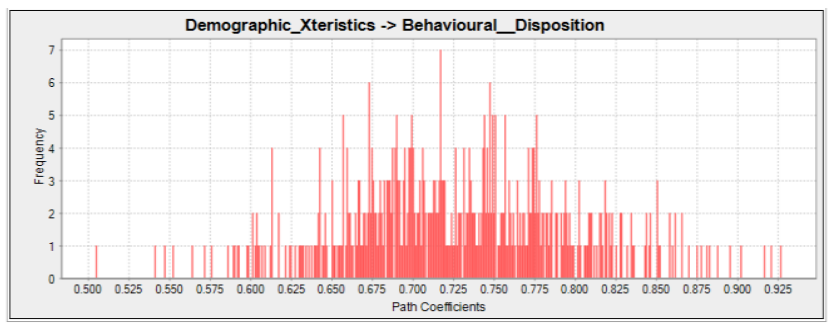

Figure 3: Path Coefficients Histogram for Demographic Characteristics and Behavioural Disposition among Women

The idea of standardisation was extended to a multivariate system, which possesses many properties, called partial regression coefficients. The term "path coefficient" indicates the use of a diagrambased approach (see Figure 1) to consider the possible causal link between a variable assumed to be a cause, and another variable assumed to be an effect as presented in Table 2.

Table 2: Path coefficients

\begin{tabular}{|c|c|c|c|c|c|}
\hline & $\begin{array}{c}R \text { - -Square } \\
\left(R^{2}\right)\end{array}$ & $\begin{array}{l}\text { R-Square } \\
\text { Adjusted }\end{array}$ & $\begin{array}{l}\text { Standard } \\
\text { Deviation } \\
\text { (STDEV) }\end{array}$ & P Values & Decision \\
\hline Awareness Level_BC & 0.224 & 0.184 & 0.393 & 0.000 & Significant \\
\hline Behaviour_Disposition & 0.749 & 0.743 & 0.404 & 0.001 & \\
\hline Demographic Xteristics & 0.426 & 0.419 & 0.353 & 0.026 & Significant \\
\hline R-Square & \multirow{2}{*}{\multicolumn{5}{|c|}{$\begin{aligned} & 0.665 \\
301.307 \mathrm{SRMR} & =0.071 \mathrm{NFI}=0.922\end{aligned}$}} \\
\hline $\begin{array}{l}\text { R-Square Adj. } \\
\text { Chi Square }\end{array}$ & & & & & \\
\hline
\end{tabular}

\section{Discussion}

The findings from this study have reverberated those of Mbuka-Ongona and Tumbo (2013) [17] and, Ganiyu and Ganiyu (2012) [26]. They all asserted that there is a high-level relationship between the strategies employed for creating awareness about breast cancer and the behavioural disposition of women to the disease in Nigeria. The persistent increase in the prevalence of breast cancer in Nigeria with seemingly non-existent solution has necessitated the need to evaluate women's level of awareness about their behavioural disposition thereby ascertaining the relevance of demographic characteristics in this regard. Several factors have contributed to the increase in the incidence of breast cancer especially in the sampled areas. According to the findings, a significant number of women in the study area have not acquired useful knowledge that could potentially be translated into diagnosing, preventing, and managing the disease.

It is therefore recommended that the government and the private sector should intensify efforts in heightening awareness creation through various media platforms to disseminate accurate information about breast self-examination. Provision should be made to make available better incentives for healthcare workers in Nigeria to optimise breast cancer service delivery. There is also a need to ensure the adequate training of Nigerian health workers on basic health education particularly concerning the early detection of breast cancer.

Compulsory, targeted and age-specific breast cancer screening should become an integral part of the healthcare services for women in Nigeria allowing for early detection and prompt intervention. The government and other major stakeholders must champion aggressive awareness campaigns on the advantages of early detection through the simple life saving procedure (BSE). Women should be made to realise the dangers of late presentation and should be encouraged to report any unusual changes in their breast to any health care facility closest to them for a professional assessment.

\section{References}

1. Agha EM, Duroshola M. Pregnancy, menopause and breast cancer: A counselling guide for women. Enugu: Cheston Ltd, 2002.

2. Ajibade JE, Ajayi MP, Allo T. Risk and investment decision making in the technological age: a dialysis of cyber fraud complication in Nigeria. International Journal of Cyber Criminology. 2016; 10(1):62-68.

3. Akinkugbe OO, Lucas AO, Onyemelukwe GC, Yahaya H, Saka MJ. Non-communicable diseases in Nigeria. Nigerian Health Review. Herfon, 2010

4. Akinsete E. PPPs: the antidote to Nigeria's healthcare infrastructure deficit. Bizwatch Nigeria. 2016. 
5. Allo TA, Edewor PA, Imhonopi D. Assessment of Perceived Risks of Breast Cancer and Breast Cancer Screening Among Women in Five Selected Local Governments in Ogun State, Nigeria. SAGE Open. 2019; 9(2). https://doi.org/10.1177/2158244019841924

6. American Cancer Society. Breast cancer prevention and early detection. 2014.

7. American Cancer Society. (ACS) What is cancer? 2015

8. Amoo EO, Olawole-Isaac A, Okorie N, Ajayi MP, Adekola PO, Amana TR, Olu-Owolabi F. Spousal desertion and coping strategies among women with cervical cancer in Nigeria: a schematic framework for wellbeing. African Population Studies. 2018; 32(1).

9. Anothaisintawee T, Wiratkapun C, Lerdsitthichai P, Kasamesup V, Wongwaisayawan S. Risk factors of breast cancer: a systematic review and meta-analysis. Asia Pac J Public Health. 2013; 25(368-387). https://doi.org/10.1177/1010539513488795 PMid:23709491

10. Anyanwu SN. Breast cancer in eastern Nigeria: a tenyear review. West African Journal of Medicine. 2000; 19 (120-125).

11. Badar F, Faruqui ZS, Ashraf A, Uddin N. Third world issues in breast cancer detection. Journal of Pakistani Medical Association. 2007; 57(137-140)

12. Bayoumi MMM, Elbasuny MMM, Nasser AMA, Abdullah KM, Almatery NMA. Saudi young females' level of knowledge regarding cervical and breast cancer. International Journal of Nursing Science. 2012; 2(5)47-52. https://doi.org/10.5923/j.nursing.20120205.01

13. Chinawa JM. Factors militating against effective implementation of primary health care (PHC) system in Nigeria. Ann Trop Med Public Health. 2015; 8(5-9). https://doi.org/10.4103/1755-6783.156701

14. Eguagie I, Okosun V. The role of primary health care in Nigerian health care delivery systems: problems and prospects. Knowledge Review. 2010; 21(1); 71-76.

15. Ekanem IA. History of cancer registration in the world and in Nigeria. Presented at Institute of Human Virology, Abuja, 2009.

16. Fornell C, Larcker DF. Evaluating structural equations with unobservable variables and measurement error. Journal of Marketing Research. 1981; 18(39-50). https://doi.org/10.1177/002224378101800104

17. Ganiy OA, Ganiyu AR. Epidemiology of Breast Cancer in Europe and Africa. Journal of Cancer Epidemiology. 2012; Article ID 915610. https://doi.org/10.1155/2012/915610 PMid:22693503 PMCid:PMC3368191

18. George TO, Allo TA, Amoo EO, Olonade O. Knowledge and attitudes about breast cancer among women: a wake-up call in Nigeria. Open Access Macedonian Journal of Medical Sciences. 2019. https://doi.org/10.3889/oamims.2019.221 PMid:31210826 PMCid:PMC6560304

19. Grunfeld EA, Ramirez AJ, Hunter MS. Richards MA. Women's knowledge and beliefs regarding breast cancer. British Journal of Cancer. 2002; 86(1373-8). https://doi.org/10.1038/sj.bjc.6600260 PMid:11986766 PMCid:PMC2375381

20. Ihekwaba FN, Ihekwaba FN. Breast cancer in Nigerian women. Breast Journal Surg. 1992; 79(771-775) https://doi.org/10.1002/bjs.1800790819 PMid:1393468

21. Jedy-Agba E, McCormack V, Olaomi O, Badejo W, Yilkudi M, Yawe T, Ezeome E, Salu I, Miner E, Anosike I, Adebamowo SN, Achusi B, dos-Santos-Silva I, Adebamowo C. Determinants of stage at diagnosis of breast cancer in Nigerian women: socio-demographic, breast cance awareness, health care access and clinical factors. Springer International Publishing Switzerland, 2017.

https://doi.org/10.1007/s10552-017-0894-y PMid:28447308 PMCid:PMC5492222

22. Justo N, Wilking N, Jönsson B, Luciani S, Cazap E. A review of breast cancer care and outcomes in Latin America. Oncologist. 2013; 18(248-256). https://doi.org/10.1634/theoncologist.2012-0373 PMid:23442305 PMCid:PMC3607519

23. Laurance JJ. Global rise in breast cancer due to Western lifestyle.
2014.

24. MacDonald DJ, Sarna L, Uman GC, Grant M, Weitzel JN. Health beliefs of women with and without breast cancer seeking genetic cancer risk assessment. Cancer Nursing. 2005; 28(5):372-379. https://doi.org/10.1097/00002820-200509000-00006 PMid:16192828

25. Mandong BM, Madaki AKJ, Manasseh AN. Malignant Disease in Jos: A follow up. Annals of African Medicine. 2004; 2(2):49-53.

26. Mbuka-Ongona D, Tumbo JM. Knowledge about breast cancer and reasons for late presentation by cancer patients seen at Princess Marina Hospital, Gaborone, Botswana. Afr J Prim Health Care Fam Med. 2013; 5(1):465. https://doi.org/10.4102/phcfm.v5i1.465 PMCid:PMC4502871

27. Modeste NN, Caleb-Drayton VL, Montgomery S. Barriers to early detection of breast cancer among women in a Caribbean population. Pan-American Journal of Public Health. 1999; 5(3):152-156. https://doi.org/10.1590/S1020-49891999000300003 PMid:10355312 28. Muanya C, Areo O. Addressing high cost of cancer treatment in Nigeria. 2018.

29. National Population Commission. Population and housing census of the Federal Republic of Nigeria, priority table. Volume iii. No. 1 Masaka Close off Olusegun Obasanjo Way Wuse Zone 7, Abuja, Nigeria, 2006.

30. Norman P, Brain K. An application of an extended health belief model to the prediction of breast self-examination among women with a family history of breast cancer. British Journal of Health Psychology. 2005; 10(1-16). https://doi.org/10.1348/135910704X24752 PMid:15826330

31. Oke M. Nigeria: Ogun should have 36 State Constituencies. Daily Trust Abuja, 2012.

32. Okobia MN, Aligbe JU. Pattern of malignant diseases at the University of Benin teaching hospital. Trop. Doct. 2005; 35(2):91-92. https://doi.org/10.1258/0049475054037147 PMid:15970031

33. Okobia MN, Osime U. Clinico-pathological study of carcinoma of the breast in Benin City. African Journal of Reproductive Health. 2001; 5(56-62). https://doi.org/10.2307/3583430 PMid:12471913

34. Okobia MN, Bunker CH, Okonofua FE, Osime U. Knowledge, attitude and practice of Nigerian women towards breast cancer: $A$ cross-sectional study. World Journal of Surgical Oncology. 2006; 4(11) https://doi.org/10.1186/1477-7819-4-11 PMid:16504034

PMCid:PMC1397833

35. Olajide TO, Ugburo AO, Habeebu MO, Lawal AO, Afolayan MO, Mofikoya MO. Awareness and practice of breast screening and its impact on early detection and presentation among breast cancer patients attending a clinic in Lagos, Nigeria. Niger Journal of Clinical Practice. 2014; 17(6):802-807. https://doi.org/10.4103/11193077.144404 PMid:25385923

36. Olanrewaju FO, Ajayi LA, Loromeke E, Olanrewaju A, Allo T, Nwannebuife $O$. Masculinity and men's health- seeking behaviour in Nigerian academia. Cogent Social Sciences. 2019; 5(1). https://www.tandfonline.com/doi/full/10.1080/23311886.2019.1682111

37. Oluwatosin OA, Oladipo O. Knowledge of breast cancer and its early detection measures among rural women in Akinyele LGA, Ibadan Nigeria. BioMed Central Cancer Journal. 2006; 6(271). https://doi.org/10.1186/1471-2407-6-271 PMid:17125524 PMCid:PMC1698502

38. Omaka-Amari NL. Ilo, CL, Nwimo IO, Onwunaka C, Umoke CI. Demographic differences in the knowledge of breast cancer among women in Ebonyi State, Nigeria. International Journal of Nursing, Midwife and Health Related Cases. 2015; 1(3):18-27.

39. Outlook. Breast cancer: Increasing incidence, limited options. 2002

40. Sheppard VB, Christopher J, Nwabukwu I. Breaking the silence barrier: Opportunities to address breast cancer in African-born women. Journal of National Medical Association 2010; 102(6):461-468. https://doi.org/10.1016/S0027-9684(15)30553-8

41. Soyingbe A. Amosun's campaign against cancer. 2013 